\title{
INHERITED THROMBOPHILIAS COULD INFLUENCE THE REPRODUCTIVE OUTCOME IN WOMEN WITH SYSTEMIC LUPUS ERYTHEMATOSUS
}

\author{
Robeva $\mathrm{R}^{1, *}$, Tanev $\mathrm{D}^{2}$, Andonova $\mathrm{S}^{3}$, Nikolova $\mathrm{M}^{4}$, \\ Tomova $\mathrm{A}^{1}$, Kumanov $\mathrm{Ph}^{1}$, Savov $\mathrm{A}^{3}$, Rashkov $\mathrm{R}^{2}$, Kolarov $\mathrm{Zl}^{2, *}$
}

*Corresponding Authors: Professor Zlatimir Kolarov, M.D., Ph.D., D.MSc., Clinic of Rheumatology, Medical University Sofia, 13 Urvich Str., Sofia 1612, Bulgaria. Tel: +359-2-958-93-91. Fax. +359-2-958-23-31. E-mail: zkolarov@abv.bg and Ralitsa Robeva, M.D., Ph.D., Clinical Center of Endocrinology and Gerontology, Medical University Sofia, 2 Zdrave Str., Sofia 1431, Bulgaria. Tel: +359-2-895-60-40. Fax:+359-2-987-41-45. E-mail: rali_robeva@yahoo.com

\section{ABSTRACT}

Systemic lupus erythematosus (SLE) is a chronic autoimmune disease associated with different reproductive complications in the affected women. Inherited thrombophilias are genetic factors increasing the risk for thromboembolism and recurrent pregnancy loss, but their influence on other reproductive disturbances in SLE patients has not been completely clarified. Two hundred and twenty-three Caucasian women (112 with SLE and 111 controls) were included in the study. Complete reproductive history of all SLE patients was carefully obtained. Genotyping for the $\mathrm{FV}_{\text {Leiden, }}, \mathrm{FII}_{\mathrm{G} 20210 \mathrm{~A}}$, and MTHFR $\mathrm{C}$ 677T $_{\text {polymorphisms }}$ was performed by polymerase chain reaction-restriction fragment length polymorphism (PCR-RFLP) analysis. No significant differences in the prevalence of the $\mathrm{FV}_{\text {Leiden }}$, FII $_{\text {G20210A }}$, and MTHFR ${ }_{\text {C677T }}$ polymorphisms between patients and controls were established. Patients with FV-

had fewer pregnancies $(0.57 \pm 0.98$ vs. $2.18 \pm 1.58$; $p=0.007$ ) than the others, while no significant differences in the reproductive history of FII ${ }_{\mathrm{G} 20210 \mathrm{~A}}$ carriers and non-carriers were observed $(p>0.05)$. In the SLE group, $41.67 \%$ of women with the MTHFR C677T TT genotype had at least one miscarriage in comparison to only $14.00 \%$ of the other female patients $(p=0.030)$. While the prevalence

\footnotetext{
${ }^{1}$ Clinical Center of Endocrinology and Gerontology, Medical University, Sofia, Medical Faculty, Sofia, Bulgaria

${ }^{2}$ Clinic of Rheumatology, Medical University, Sofia, Medical Faculty, Sofia, Bulgaria

${ }^{3}$ National Genetic Laboratory, University Specialized Hospital for Active Treatment in Obstetrics and Gynecology, "Maichin dom", Medical University, Sofia, Medical Faculty, Sofia, Bulgaria

${ }^{4}$ Clinic of Nephrology, Medical University, Sofia, Medical Faculty, Sofia, Bulgaria
}

of the investigated thrombophilias was similar in patients with SLE and healthy women, a substantial influence of the inherited prothrombotic factors on the reproductive history of patients was revealed. The investigations of the $\mathrm{FV}_{\text {Leiden }}$ and MTHFR ${ }_{\mathrm{C} 677 \mathrm{~T}}$ polymorphisms in SLE patients could help to identify women at highest risk for reproductive failure and thus, further studies in other ethnic groups would be of strong clinical importance.

Keywords: Autoimmunity; Miscarriages; Reproduction; Systemic lupus erythematosus (SLE); Thrombophilias.

\section{INTRODUCTION}

Systemic lupus erythematosus (SLE) is a chronic autoimmune disease that could increase the risk for adverse pregnancy outcomes in affected women because of the associated hypercoagulability [1]. The SLE exacerbations, active SLE at conception, presence of anti-phospholipid antibodies, lupus nephritis and hypertension have been reported as important risk factors for obstetric complications [2,3]. However, the role of genetically determined thrombophilias for women with SLE has not yet been completely clarified.

A well-known prothrombotic factor is the single nucleotide substitution in the factor $V$ gene (rs6025, G>A substitution at nucleotide position 1691), which encodes a resistant to activated protein C molecule (Factor V Leiden) [4]. Other common thrombophilias include a prothrombin gene G20210A variant (rs1799963) that has been associated with elevated prothrombin activity as well as $\mathrm{C}>\mathrm{T}$ transition at base pair 677 of the methylenetetrahydrofolate re-ductase (MTHFR) gene (rs1801133) (CC, CT and TT genotypes), which has been related to increased plasma homocysteine levels $[5,6]$. 
Several studies have investigated the influence of Factor V Leiden and prothrombin G20210A polymorphisms on thrombosis prevalence in lupus patients [7-12]. Additionally, some authors discuss the presence of recurrent miscarriages and fetal losses in SLE women with inherited thrombophilias [8,11], but no definitive conclusions occur. The present study aimed to investigate associations between the reproductive history of women with lupus and the common thrombophilic polymorphisms including Factor V Leiden $\left(\mathrm{FV}_{\text {Leiden }}\right)$, prothrombin G20210A (FII) and MTHFR C677T.

\section{MATERIALS AND METHODS}

Subjects. Two hundred and twenty-three Caucasian women [mean age $40.77 \pm 11.94$ years (20-68)] were included in the study. One hundred and twelve patients fulfilled the modified 1997 American College Rheumatology (ACR) classification criteria for SLE [13]. Secondary antiphospholipid syndrome (sAPS) according to the accepted criteria was presented in $15.18 \%$ of them [14]. All women underwent a complete general assessment and filled-out questionnaires on their reproductive history. The age of menarche, menstrual regularity (before the SLE onset and treatment), infertility, number of pregnancies, miscarriages, intentional abortions, stillbirths (fetal loss after 20 gestational weeks) and live children were self-reported. One hundred and eleven controls were collected from the medical staff and students. They were all clinically healthy women without known connective tissue diseases. The experimental protocol was explained to all participants and written informed consent was obtained. The study was approved by the institutional Ethics Committee.

Genetic Assay. All participating women provided peripheral blood samples for DNA collected in EDTA vacutainers. Genomic DNA was extracted with a stan- dard salt extraction procedure. Genotyping for the $\mathrm{FV}_{\text {Leiden }}$, FII $_{\text {G20210A }}$ and MTHFR ${ }_{\mathrm{C} 677 \mathrm{~T}}$ polymorphisms was performed by polymerase chain reaction-restriction fragment length polymorphism (PCR-RFLP) analysis [15]. The control group of women was used only for a comparison of the genetic polymorphism prevalence. The distribution of all investigated genotypes in healthy females was in agreement with the Hardy-Weinberg equilibrium.

Statistical Analyses. The results were presented as mean \pm standard deviation (SD) (median) for continuous variables or as a frequency (\%). Categorical data were analyzed by the $\chi^{2}$ test or Fisher's exact test. Differences between two groups were established with a Mann-Whitney test, while a Kruskal-Wallis test was used for comparisons of the three groups. Logistic regression analysis was used where appropriate. A $p$ value of 0.05 was considered significant. Statistical analysis was conducted by the Statistical Package for the Social Sciences (SPSS), for Windows (SPSS Inc., Chicago, IL, USA).

\section{RESULTS}

No significant differences in the prevalence of the $\mathrm{FV}_{\text {Leiden }}, \mathrm{FII}_{\mathrm{G} 20210 \mathrm{~A}}$ and MTHFR $\mathrm{C}$ 677T $_{\text {T }}$ polymorphisms between patients and controls were established (Table 1), although the frequency of heterozygous MTHFR $_{\mathrm{C} 677 \mathrm{~T}}$ carriers in SLE patients was increased. The differences in the reproductive history of patients with $\mathrm{FV}_{\text {Leiden }}$ or $\mathrm{FII}_{\mathrm{G} 20210 \mathrm{~A}}$ polymorphisms are presented on Table 2. Patients with $\mathrm{FV}_{\text {Leiden }}$ had fewer pregnancies and live births than the others, while no significant differences in the reproductive history of FII $_{\mathrm{G} 20210 \mathrm{~A}}$ carriers and non-carriers were observed (Table 2). The logistic regression analysis showed that the presence of $\mathrm{FV}_{\text {Leiden }}$ but not the $\mathrm{FII}_{\mathrm{G} 20210 \mathrm{~A}}$ decreased significantly the chance for having at least one live birth even after adjustment for the current age of patients and

Table 1. Prevalence of the investigated genetic polymorphisms in patients with SLE and healthy women. N: normal allele; M: polymorphic allele. Genotypes: NN: two normal alleles; NM: heterozygous state. No homozygous carriers of FV or FII G20210A were found and none of the patients had both mutations. MTHFR ${ }_{\text {C677T }}$ genotypes: CC: two normal alleles; TT: two polymorphic alleles; CT: heterozygous state.

\begin{tabular}{|c|c|c|c|c|c|}
\hline & \multicolumn{2}{|c|}{ Controls } & \multicolumn{2}{|c|}{ SLE Patients } & \multirow[t]{2}{*}{$p$ Value } \\
\hline $\mathrm{FV}_{\text {Leiden }}$ & \multicolumn{2}{|l|}{$\mathrm{NN}$} & $\mathrm{NN}$ & $\mathrm{NM}$ & \\
\hline$n=220$ & \multicolumn{2}{|c|}{$100(91.7 \%)$} & $104(93.7 \%)$ & $7(6.3 \%)$ & 0.613 \\
\hline $\mathrm{FII}_{\mathrm{G} 20310 \mathrm{~A}}$ & \multicolumn{2}{|l|}{$\mathrm{NN}$} & $\mathrm{NN}$ & $\mathrm{NM}$ & \\
\hline$n=223$ & \multicolumn{2}{|c|}{$105(94.6 \%)$} & $106(94.6 \%)$ & $6(5.4 \%)$ & 1.000 \\
\hline MTHFR $_{\text {C677T }}$ & $\mathrm{CC}$ & & $\mathrm{CC}$ & $\mathrm{TT}$ & \\
\hline$n=223$ & $47(42.3 \%)$ & & $36(32.2 \%)$ & $(10.7 \%)$ & 0.061 \\
\hline
\end{tabular}


Table 2. Main reproductive characteristics of SLE patients in association with the FV

(2C) genetic polymorphisms. SLE: systemic lupus erythematosus; ACR: American College of Rheumatology classification C677T $_{\text {Leiden }}$ (2A) criteria; sAPS: secondary antiphospholipid syndrome. [The values are expressed as mean \pm SD (median).]

\begin{tabular}{|l|c|c|c|}
\hline Table 2A. Main reproductive characteristics in SLE patients with the $\mathrm{FV}_{\text {Leiden }}$ polymorphism & FV $_{\text {Leiden }}[-]$ & $\boldsymbol{p}$ Value \\
\hline & FV $_{\text {Leiden }}[+]$ & $42.75 \pm 11.82(42.50)$ & 0.649 \\
\hline Age (years) & $40.43 \pm 11.18(37.00)$ & $35.03 \pm 12.12(34.50)$ & 0.743 \\
\hline Age at diagnosis (years) & $33.71 \pm 15.50(34.00)$ & $5.37 \pm 1.32(5.00)$ & 0.821 \\
\hline ACR criteria number & $5.43 \pm 1.27(5.00)$ & $13.83 \pm 1.63(14.00)$ & 0.199 \\
\hline Age at menarche (years) & $14.43 \pm 0.79(15.00)$ & $85.58 \%$ & 0.291 \\
\hline Menstrual regularity & $71.43 \%$ & $2.18 \pm 1.58(2.00)$ & $\mathbf{0 . 0 0 7}$ \\
\hline Number of pregnancies & $0.57 \pm 0.98(0.00)$ & $0.23 \pm 0.53(0.00)$ & 0.218 \\
\hline Number of miscarriages & $0.00(0.00)$ & $22.11 \%$ & 0.341 \\
\hline Miscarriage or stillbirth & $0.00(0.00)$ & $0.55 \pm 1.00(0.00)$ & 0.088 \\
\hline Number of abortions & $0.00(0.00)$ & $1.33 \pm 0.93(1.00)$ & $\mathbf{0 . 0 4 9}$ \\
\hline Number of live births & $0.57 \pm 0.98(0.00)$ & $9.61 \%$ & 1.000 \\
\hline Infertility & $0.00 \%$ & $15.38 \%$ & 1.000 \\
\hline sAPS & $14.28 \%$ & & \\
\hline
\end{tabular}

Table 2B. Main reproductive characteristics of SLE patients in association with the $\mathrm{FII}_{\mathrm{G} 20210 \mathrm{~A}}$ polymorphism

\begin{tabular}{|l|c|c|c|}
\hline & FII $_{\text {G20210A }}[+]$ & FII $_{\text {G20210A }}[-]$ & $p$ Value \\
\hline Age (years) & $42.83 \pm 12.78(44.00)$ & $42.50 \pm 11.73(42.00)$ & 0.959 \\
\hline Age at diagnosis (years) & $29.83 \pm 13.15(29.50)$ & $35.06 \pm 12.31(34.50)$ & 0.386 \\
\hline ACR criteria number & $5.67 \pm 1.50(5.00)$ & $5.38 \pm 1.31(5.00)$ & 0.607 \\
\hline Age at menarche (years) & $15.00 \pm 2.28(14.50)$ & $13.80 \pm 1.52(14.00)$ & 0.290 \\
\hline Menstrual regularity & $83.33 \%$ & $84.91 \%$ & 1.000 \\
\hline Number of pregnancies & $2.50 \pm 1.05(2.50)$ & $2.04 \pm 1.63(2.00)$ & 0.342 \\
\hline Number of miscarriages & $0.33 \pm 0.52(0.00)$ & $0.21 \pm 0.51(0.00)$ & 0.322 \\
\hline Miscarriage or stillbirth & $33.33 \%$ & $19.81 \%$ & 0.601 \\
\hline Number of abortions & $0.67 \pm 0.82(0.50)$ & $0.50 \pm 0.99(0.00)$ & 0.313 \\
\hline Number of live births & $1.33 \pm 0.52(1.00)$ & $1.26 \pm 0.97(1.00)$ & 0.870 \\
\hline Infertility & $0.00 \%$ & $9.43 \%$ & 1.000 \\
\hline sAPS & $16.67 \%$ & $15.09 \%$ & 1.000 \\
\hline
\end{tabular}

\begin{tabular}{|l|c|c|c|c|}
\hline \multicolumn{5}{|l|}{ Table 2C. Main reproductive characteristics of SLE patients in association with the MTHFR ${ }_{\text {C677T }}$ polymorphism } \\
\hline MTHFR $_{\text {C677T }}$ & CC & CT & TT & $p$ Value \\
\hline Age (years) & $42.53 \pm 11.46(40.50)$ & $41.73 \pm 12.17(42.00)$ & $46.67 \pm 9.99(47.50)$ & 0.400 \\
\hline Age at diagnosis (years) & $34.67 \pm 11.86(35.00)$ & $34.20 \pm 12.91(32.50)$ & $38.17 \pm 11.08(37.50)$ & 0.599 \\
\hline ACR criteria number & $5.44 \pm 1.38(5.00)$ & $5.30 \pm 1.28(5.00)$ & $5.75 \pm 1.36(6.00)$ & 0.504 \\
\hline Age at menarche (years) & $13.64 \pm 1.46(14.00)$ & $13.91 \pm 1.60(14.00)$ & $14.33 \pm 1.87(14.50)$ & 0.307 \\
\hline Menstrual regularity & $91.67 \%$ & $81.25 \%$ & $83.33 \%$ & 0.398 \\
\hline Number of pregnancies & $2.25 \pm 1.42(2.00)$ & $1.88 \pm 1.73(1.00)$ & $2.50 \pm 1.31(2.00)$ & 0.146 \\
\hline Number of miscarriages & $0.19 \pm 0.47(0.00)$ & $0.16 \pm 0.44(0.00)$ & $0.58 \pm 0.79(0.00)$ & $\mathbf{0 . 0 4 0}$ \\
\hline Miscarriage or stillbirth & $19.44 \%$ & $17.18 \%$ & $41.66 \%$ & 0.181 \\
\hline Number of abortions & $0.64 \pm 0.96(0.00)$ & $0.50 \pm 1.05(0.00)$ & $0.17 \pm 0.39(0.00)$ & 0.223 \\
\hline Number of live births & $1.36 \pm 0.99(1.00)$ & $1.16 \pm 0.95(1.00)$ & $1.58 \pm 0.79(2.00)$ & 0.287 \\
\hline Infertility & $16.67 \%$ & $4.69 \%$ & $8.33 \%$ & 0.085 \\
\hline sAPS & $16.66 \%$ & $10.94 \%$ & $33.33 \%$ & 0.135 \\
\hline
\end{tabular}


the presence of sAPS [0.041 (0.004-0.400), $p=0.006]$. The $\mathrm{FV}_{\text {Leiden }}$ or $\mathrm{FII}_{\mathrm{G} 20210 \mathrm{~A}}$ polymorphisms did not influence significantly the risk for at least one unsuccessful pregnancy (miscarriage or stillbirth) $(p>0.05)$.

The reproductive history of patients according to the presence of MTHFR $_{\mathrm{C} 677 \mathrm{~T}}$ polymorphism is presented in Table 2. Among women with the TT genotype, $41.67 \%$ had at least one miscarriage in comparison to $14.00 \%$ of the other female patients $(p=0.030)$, while the prevalence of self-reported infertility and number of pregnancies was similar in MTHFR ${ }_{\mathrm{C} 677 \mathrm{~T}}$ TT homozygotes in comparison to MTHFR $_{\text {C677T }}$ C allele carriers. The presence of MTHFR ${ }_{\text {C677T }}$ TT increased more than three times the risk for at least one miscarriage in SLE patients after adjustment for age [odds ratio (OR) 3.827 (1.013-14.459), $p=0.048$ ] but the association was attenuated after adjustment for age and sAPS [OR 2.765 (0.607-12.604), $p=0.189]$.

Recurrent pregnancy loss (two or more miscarriages) was reported by six $(5.4 \%)$ of the patients. It was not related to any of the investigated polymorphisms $(p>0.1$ for all).

\section{DISCUSSION}

Factor V Leiden and FII ${ }_{\mathrm{G} 20210 \mathrm{~A}}$ are the most frequently investigated genetic polymorphisms related to hypercoagulability, venous thromboembolism and recurrent pregnancy loss $[16,17]$. Both polymorphisms were thoroughly investigated in SLE patients, but the studies were focused primarily on disease-related thrombotic events $[9,11]$. The largest study that investigated risk factors for thrombosis in SLE patients suggested that the genetic predisposition for obstetric and non-obstetric thrombosis in lupus patients might be similar [11]. Accordingly, the present study aimed to investigate the influence of inherited thrombophilias on some reproductive aspects of SLE women. The results showed that the $\mathrm{FV}_{\text {Leiden }}$ allele carriers reported a lower number of pregnancies and live births irrespective of the presence of the sAPS. As the self-reported prevalence of menstrual irregularities was similar in both groups, an increased frequency of unrecognized chemical pregnancy loss is one of the possible hypotheses. Factor V Leiden was already associated with a higher rate of preclinical pregnancy losses and very early recurrent miscarriages in otherwise healthy women $[18,19]$. The mutant allele was not associated with fetal losses in the investigated SLE patients, although in healthy women $\mathrm{FV}_{\text {Leiden }}$ increased the risk for second trimester miscarriages and stillbirths due to uteroplacental insufficiency [19-21]. As $\mathrm{FV}_{\text {Leiden }}$ and lupus are both independently related to a resistance against ac- tivated protein $\mathrm{C}$ and hypercoagulability, their synergistic effect could lead to an earlier miscarriage than in women without the autoimmune disease [22]. Ineffective blood flow caused by a vascular insufficiency in the trophoblast might impair the developing pregnancy in mothers with several prothrombotic risk factors [18]. Contrary to our results, Regéczy et al. [8] found significantly higher prevalence of fetal losses in $\mathrm{FV}_{\text {Leiden }}$ carriers than in other SLE women. The discrepancies could be explained by the low number of mutation carriers, different characteristics of SLE patient groups and ethnic peculiarity, but nevertheless, both studies showed that $\mathrm{FV}_{\text {Leiden }}$ could be an important genetic factor in the deteriorating reproductive outcomes in lupus patients.

The prevalence of the G20210A polymorphism in the prothrombin gene did not increase the risk for SLE development and did not influence the thrombotic risk in patients with lupus $[9,11,23]$. FII ${ }_{\mathrm{G} 20210 \mathrm{~A}}$ was related to increased prevalence of recurrent miscarriages in the general population [17], but data concerning SLE patients were scarce. The present study did not find any significant associations between the mutant allele and the reproductive outcomes in SLE patients. However, no definitive conclusions could be drawn, because of the small number of FII $_{\mathrm{G} 20210 \mathrm{~A}}$ carriers.

The MTHFR $_{\mathrm{C} 677 \mathrm{~T}}$ polymorphism was widely investigated in different thrombotic and cancer diseases, and ethnic-dependent associations were found [24,25]. The prevalence of the MTHFR $_{\mathrm{C} 677 \mathrm{~T}}$ polymorphism was also investigated in SLE patients [26,27]. Afeltra et al. [26] found an increased frequency of TT but not CT genotypes in lupus patients compared to controls, while Summers et al. [27] did not find any differences. Our data did not show significant differences between patients and controls, although the prevalence of heterozygous CT carriers in SLE patients was increased. Further larger studies are needed to establish the possible influence of the MTH$\mathrm{FR}_{\mathrm{C} 677 \mathrm{~T}}$ polymorphism on SLE development.

According to our results the MTHFR $_{\mathrm{C} 677 \mathrm{~T}}$ TT genotype increased the risk of at least one miscarriage in lupus women. MTHFR $_{\mathrm{C} 677 \mathrm{~T}}$ was significantly associated with recurrent miscarriages in Asian women, while the results in Caucasians were conflicting [28-30]. After adjustment for sAPS, the association between MTHFR $_{\mathrm{C} 677 \mathrm{~T}}$ polymorphism and spontaneous abortion was attenuated, thus, synergistic effects of the immunological and genetic factors in SLE could not be excluded.

The main limitations of the study were the small number of pregnancies in the group of SLE patients as well as the self-reported reproductive history without data from medical records where other confounding factors could 
be included. Nevertheless, the present data showed that inherited thrombophilias could influence the reproductive outcome in women with SLE. Interestingly, the same polymorphisms modulate the thrombosis risk in EuropeanAmerican SLE patients [11]. Thus, further studies in other ethnic groups would be of strong clinical importance.

\section{ACKNOWLEDGMENTS}

The present study was financially supported by the Medical University Sofia [Grant 26/2010, Grant 13/2013].

Declaration of Interest. The authors report no conflicts of interest. The authors alone are responsible for the content and writing of this article.

\section{REFERENCES}

1. Dhar P, Sokol R. Thrombophilia in systemic lupus erythematosus: A review of multiple mechanisms and resultant clinical outcomes. In: Ivanov P, Ed. Pregnancy Thrombophilia - The Unsuspected Risk. INTECH, 2013 (http://dx.doi.org/10.5772/56902).

2. Smyth A, Oliveira GH, Lahr BD, Bailey KR, Norby SM, Garovic VD. A systematic review and metaanalysis of pregnancy outcomes in patients with systemic lupus erythematosus and lupus nephritis. Clin J Am Soc Nephrol. 2010; 5(11): 2060-2068.

3. Al Arfaj AS, Khalil N. Pregnancy outcome in 396 pregnancies in patients with SLE in Saudi Arabia. Lupus. 2010; 19(14): 1665-1673.

4. Bertina RM, Koeleman BP, Koster T, Rosendaal FR, Dirven RJ, de Ronde H, et al. Mutation in blood coagulation factor $\mathrm{V}$ associated with resistance to activated protein C. Nature. 1994; 369(6475): 64-67.

5. von Ahsen N, Lewczuk P, Schütz E, Oellerich M, Ehrenreich $\mathrm{H}$. Prothrombin activity and concentration in healthy subjects with and without the prothrombin G20210A mutation. Thromb Res. 2000; 99(6): 549-556.

6. Brattstrom L, Wilcken DE, Ohrvik J, Brudin L. Common methylenetetrahydrofolate reductase gene mutation leads to hyperhomocysteinemia but not to vascular disease: The result of a meta-analysis. Circulation. 1998; 98(23): 2520-2526.

7. Fijnheer R, Horbach DA, Donders RC, Vilé H, von Oort E, Nieuwenhuis HK, et al. Factor V Leiden, antiphospholipid antibodies and thrombosis in systemic lupus erythematosus. Thromb Haemost. 1996; 76(4): 514-517.
8. Regéczy N, Lakos G, Balogh I, Ajzner E, Kiss E, Szegedi G. The Leiden mutation of coagulation factor V in Hungarian SLE patients. Clin Appl Thromb Hemost. 2000; 6(1): 41-45.

9. Vayá A, Santaolaria M, Micó L, Calvo J, Oropesa R, Villa $\mathrm{P}$, et al. Thrombotic events in systemic lupus erythematosus. Its association with acquired and inherited thrombophilic defects. Clin Hemorheol Microcirc. 2008; 40(2): 79-87.

10. Kaiser R, Barton JL, Chang M, Catanese JJ, Li Y, Begovich $\mathrm{AB}$, et al. Factor V Leiden and thrombosis in patients with systemic lupus erythematosus: A meta-analysis. Genes Immun. 2009; 10(5): 495-502.

11. Kaiser R, Li Y, Chang M, Catanese J, Begovich AB, Brown EE, et al. Genetic risk factors for thrombosis in systemic lupus erythematosus. J Rheumatol. 2012; 39(8): 1603-1610.

12. Brouwer JL, Bijl M, Veeger NJ, Kluin-Nelemans HC, van der Meer J. The contribution of inherited and acquired thrombophilic defects, alone or combined with antiphospholipid antibodies, to venous and arterial throm-boembolism in patients with systemic lupus erythematosus. Blood. 2004; 104(1): 143-148.

13. Hochberg MC. Updating the American College of Rheumatology revised criteria for classification of systemic lupus erythematosus. Arthritis Rheum. 1997; 40(9): 1725.

14. Keeling D, Mackie I, Moore GW, Greer IA, Greaves M; British Committee for Standards in Haematology. Guidelines on the investigation and management of antiphospholipid syndrome. Br J Haematol. 2012; 157(1): 47-58.

15. Koleva R, Dimitrova V, Chernev T, Savov A, Karagjozova $\mathrm{Zh}$, Mazneykova $\mathrm{V}$, et al. Impact of inherited thrombophilia on the development of some pregnancy complications. Akush Ginekol (Sofia). 2005; 44(5): $18-26$

16. Simone B, De Stefano V, Leoncini E, Zacho J, Martinelli I, Emmerich J, et al. Risk of venous thromboembolism associated with single and combined effects of Factor V Leiden, Prothrombin 20210A and Methylene-tethraydrofolate reductase C677T: A meta-analysis involving over 11,000 cases and 21,000 controls. Eur J Epidemiol. 2013; 28(8): 621-647.

17. Bradley LA, Palomaki GE, Bienstock J, Varga E, Scott JA. Can Factor V Leiden and prothrombin G20210A testing in women with recurrent pregnancy loss result in improved pregnancy outcomes? Results 
from a targeted evidence-based review. Genet Med. 2012; 14(1): 39-50.

18. Tal J, Schliamser LM, Leibovitz Z, Ohel G, Attias D. A possible role for activated protein $\mathrm{C}$ resistance in patients with first and second trimester pregnancy failure. Hum Reprod. 1999; 14(6): 1624-1627.

19. Reznikoff-Etiévan MF, Cayol V, Carbonne B, Robert A, Coulet F, Milliez J. Factor V Leiden and G20210A prothrombin mutations are risk factors for very early recurrent miscarriage. BJOG 2001; 108(12): 1251-1254.

20. Preston FE, Rosendaal FR, Walker ID, Briët E, Berntorp E, Conard J, et al. Increased fetal loss in women with heritable thrombophilia. Lancet. 1996; 348(9032): 913-916.

21. Spina V, Aleandri V, Morini F. The impact of the factor V Leiden mutation on pregnancy. Hum Reprod Update. 2000; 6(3): 301-306.

22. Meesters EW, Hansen H, Spronk HM, Hamulyak K, Rosing J, Rowshani AT, et al. The inflammation and coagulation cross-talk in patients with systemic lupus erythematosus. Blood Coagul Fibrinolysis. 2007; 18(1): 21-28.

23. Demirci FY, Dressen AS, Kammerer CM, Barmada MM, Kao AH, Ramsey-Goldman R, et al. Functional polymorphisms of the coagulation factor II gene (F2) and susceptibility to systemic lupus erythematosus. J Rheumatol. 2011; 38(4): 652-657.

24. Gohil R, Peck G, Sharma P. The genetics of venous thromboembolism. A meta-analysis involving approximately 120,000 cases and 180,000 controls. Thromb Haemost. 2009; 102(2): 360-370.
25. Teng Z, Wang L, Cai S, Yu P, Wang J, Gong J, et al. The $677 \mathrm{C}>\mathrm{T}$ ( $\mathrm{rs} 1801133)$ polymorphism in the MTHFR gene contributes to colorectal cancer risk: A meta-analysis based on 71 research studies. PLoS One 2013; 8(2):e55332. doi: 10.1371/journal. pone.0055332.

26. Afeltra A, Vadacca M, Conti L, Galluzzo S, Mitterhofer AP, Ferri GM, et al. Thrombosis in systemic lupus erythematosus: Congenital and acquired risk factors. Arthritis Rheum. 2005; 53(3): 452-459.

27. Summers CM, Cucchiara AJ, Nackos E, Hammons AL, Mohr E, Whitehead AS, et al. Functional polymorphisms of folate-metabolizing enzymes in relation to homocysteine concentrations in systemic lupus erythematosus. J Rheumatol. 2008; 35(11): 2179-2186.

28. Wu X, Zhao L, Zhu H, He D, Tang W, Luo Y. Association between the MTHFR C677T polymorphism and recurrent pregnancy loss: A meta-analysis. Genet Test Mol Biomarkers. 2012; 16(7): 806-811.

29. Baumann K, Beuter-Winkler P, Hackethal A, Strowitzki T, Toth B, Bohlmann MK. Maternal factor V Leiden and prothrombin mutations do not seem to contribute to the occurrence of two or more than two consecutive miscarriages in Caucasian patients. Am J Reprod Immunol. 2013; 70(6): 518-521.

30. Ozdemir O, Yenicesu GI, Silan F, Köksal B, Atik $\mathrm{S}$, Ozen $\mathrm{F}$, et al. Recurrent pregnancy loss and its relation to combined parental thrombophilic gene mutations. Genet Test Mol Biomarkers. 2012; 16(4): 279-286. 